\title{
Demand for Beef and Chicken Products: Separability and Structural Change
}

\author{
James S. Eales; Laurian J. Unnevehr
}

American Journal of Agricultural Economics, Vol. 70, No. 3. (Aug., 1988), pp. 521-532.

Stable URL:

http://links.jstor.org/sici?sici=0002-9092\%28198808\%2970\%3A3\%3C521\%3ADFBACP\%3E2.0.CO\%3B2-V

American Journal of Agricultural Economics is currently published by American Agricultural Economics Association.

Your use of the JSTOR archive indicates your acceptance of JSTOR's Terms and Conditions of Use, available at

http://www.jstor.org/about/terms.html. JSTOR's Terms and Conditions of Use provides, in part, that unless you have obtained prior permission, you may not download an entire issue of a journal or multiple copies of articles, and you may use content in the JSTOR archive only for your personal, non-commercial use.

Please contact the publisher regarding any further use of this work. Publisher contact information may be obtained at http://www.jstor.org/journals/aaea.html.

Each copy of any part of a JSTOR transmission must contain the same copyright notice that appears on the screen or printed page of such transmission.

The JSTOR Archive is a trusted digital repository providing for long-term preservation and access to leading academic journals and scholarly literature from around the world. The Archive is supported by libraries, scholarly societies, publishers, and foundations. It is an initiative of JSTOR, a not-for-profit organization with a mission to help the scholarly community take advantage of advances in technology. For more information regarding JSTOR, please contact support@ jstor.org. 


\title{
Demand for Beef and Chicken Products: Separability and Structural Change
}

\author{
James S. Eales and Laurian J. Unnevehr
}

\begin{abstract}
Dynamic almost ideal demand systems are estimated for meat aggregates and for disaggregated meat products. Tests for weak separability show that consumers choose among meat products rather than meat aggregates such as "beef"' or "chicken." Therefore, tests for structural change in the meat aggregates may be biased. Tests for structural change in the meat products show an exogenous constant annual $6.4 \%$ growth in chicken parts demand from 1965 to 1985 and a $3.5 \%$ decline in beef table cut demand after 1974. Increased demand for convenience may explain these changes.
\end{abstract}

Key words: almost ideal demand systems, consumer demand, meat products, structural change, weak separability.

Several studies have indicated that the recent shift from beef to poultry in consumption is not entirely caused by changes in relative prices or income (Braschler, Chavas, Dahlgran, Hudson and Vertin, Moschini and Meilke, Frank, Thurman). Most studies of structural change have focused on red meat consumption; only Thurman has looked closely at the poultry market, and no one has considered poultry products. Yet, the mix of chicken products marketed changed dramatically during the last twenty years and should have influenced aggregate meat demand. The share of broiler slaughter marketed as whole birds declined from $74 \%$ in 1965 to $28 \%$ in 1985 , while cut-up parts and processed chicken products increased from $26 \%$ to $72 \%$. Whole birds are inferior goods, and cut-up parts and processed chicken are normal goods (Haidacher et al.). The shift in chicken product mix away from whole birds should have increased the preference for total chicken.

In this article two related questions are addressed. First, do consumers allocate expenditures among meats by animal origin or byproduct type? Second, does disaggregation of meat into products in a meat demand model give insight into the causes of structural

James S. Eales and Laurian J. Unnevehr are assistant professors of agricultural economics at the University of Illinois.

This study was supported in part by a grant from the University of Illinois Research Board and Project No. 358 of the Agricultural Experiment Station, College of Agriculture, University of Illinois.

The authors wish to thank Gerald C. Nelson, Michael Wohlgenant, and an anonymous reviewer for comments. change? To answer these questions, two meat demand systems are estimated with the almost ideal demand system (AIDS) of Deaton and Muellbauer (1980a,b). The first system includes aggregate chicken, beef, and pork; the second system disaggregates chicken into whole birds and parts/processed products, and beef into hamburger and table cuts.

Tests of weak separability are performed for various groups of meat products in order to understand how consumers allocate their meat expenditures. If meat products are not weakly separable by animal type, such as "beef" and "chicken," then it is better to disaggregate meats into their constituent products to understand preference changes.

All demand equations are then tested for structural change. One hypothesis is that changes in product mix are a major cause of structural change. For example, if an exogenous shift in aggregate chicken demand is observed and none is found in either chicken product, then the change in product mix, rather than preferences, is causing the apparent shift in total chicken demand. An alternative hypothesis is that an aggregate shift reflects preference changes in the product demand equations, and these changes may be concentrated in particular types of products.

\section{The AIDS Model}

The AIDS model (Deaton and Muellbauer 1980a) satisfies the axioms of choice exactly, 
allows consistent aggregation of microlevel demands up to a market demand function, and does not require additive preferences. ${ }^{1}$ It has been applied to economy-level data by Deaton and Muellbauer (1980a) and Blanciforti et al.; to food groupings by Blanciforti, Green, and King; Capps, Tedford, and Havlicek; and to meats by Chalfant and Alston.

Detailed derivations of the model are available in Deaton and Muellbauer (1980a,b). The general form of the derived share equations is

$$
w_{i}=\alpha_{i}+\sum_{j} \gamma_{i j} \ln \left(p_{j}\right)+\beta_{i} \ln (X / P)
$$

for all $i$,

where $w_{i}$ is the expenditure share of the $i$ th commodity, $p_{j}$ are prices, $X$ is total expenditure on all commodities in the system, and

$$
\begin{aligned}
\ln (\boldsymbol{P})= & \alpha_{0}+\sum_{i} \alpha_{i} \ln \left(p_{i}\right) \\
& +1 / 2 * \sum_{i} \sum_{j} \gamma_{i j} \ln \left(p_{i}\right) \ln \left(p_{j}\right)
\end{aligned}
$$

is a price index. The basic demand restrictions - adding up, homogeneity, and symmetry-are expressed in terms of the model's coefficients:

$$
\begin{aligned}
\sum_{i} \alpha_{i}=1 \quad \sum_{i} \gamma_{i j}=0 \quad \sum_{i} \beta_{i}=0 \\
\sum_{j} \gamma_{i j}=0 \quad \text { (homogeneity) } \\
\gamma_{i j}=\gamma_{j i} \quad \text { (symmetry) }
\end{aligned}
$$

and may be imposed or tested. Since previous studies of meat demand have found that dynamics are important (Pope, Green, and Eales; Chavas; Blanciforti et al.) we follow Deaton and Muellbauer and use the firstdifference form of equation $(1) ;^{2}$ that is:

$$
\Delta w_{i}=\sum_{j} \gamma_{i j} \Delta \ln \left(p_{j}\right)+\beta_{i} \Delta \ln (X / P)
$$

for all $i$.

\footnotetext{
1 Other functional forms have been advocated for the meat complex. In this study a primary concern is the aggregation of demand across products. The consistent aggregation of microlevel to market demand property of the AIDS model removes a possible source of aggregation bias.

${ }^{2}$ Blanciforti, Green, and King assumed a different form for the dynamic adjustment in demand which led to including a lagged dependent variable on the right-hand side of equation (1). Such a formulation of the present model produced similar, but marginally inferior, results.
}

As it stands the system of equations (4) is nonlinear. A final simplification is to approximate $\ln (P)$ in equation (2) with Stone's price index. (Although Stone's index is $\ln (P)=$ $\sum_{j} w_{j t} \ln \left(p_{j t}\right)$, we use $\sum_{j} w_{j t-1} \ln \left(p_{j t}\right)$ to avoid simultaneity problems.) With this simplification, the system of equations (4) is linear in the parameters and the approximation will be excellent as long as prices are collinear (Deaton and Muellbauer, pp. 316-17).

Changes in income distribution may have affected aggregate meat demand during the last fifteen years (Unnevehr). The AIDS system allows for correction of the total expenditure variable to reflect changes in the distribution of expenditures. Average expenditure, $X$, is divided by an index, $k$, to obtain the representative budget level, $X^{o}$, where

$$
\begin{aligned}
k & =Z / H, \\
\ln Z & =-\Sigma_{i} s_{i} \ln \left(s_{i}\right),
\end{aligned}
$$

$s_{i}$ is the share of income of household group $i$, and $H$ is the number of household groups (Deaton and Muellbauer 1980a, pp. 314-15). The $k$ index is identical to Theil's entropy measure of equality and decreases as inequality increases. Therefore, representative expenditure will be larger as inequality increases. In the final estimation, $X$ in equation (4) is replaced by $X^{o}$.

Both aggregated and disaggregated chicken and beef are estimated in the AIDS model together with pork, other foods, and all other goods. This allows the use of total per capita expenditures instead of meat expenditures as an explanatory variable, which makes possible broad tests for separability, correction for income distribution effects, and estimates of expenditure elasticities that are comparable with other results. It also permits calculation of compensated elasticities.

The model was estimated using iterative Zellner's seemingly unrelated regressions model $(1962,1963)$ with the other goods equation dropped due to the adding-up restriction (Deaton and Muellbauer 1980a, Berndt and Savin). Tests of homogeneity and symmetry in the first difference AIDS models were not rejected (insignificant at the .05 level), so these restrictions were imposed. In preliminary estimation of the static AIDS model [equation (1)], the homogeneity condition was rejected. (This was another motivation for using the first difference form of the model.) 


\section{Tests for Separability and Structural Change}

The concept of separability is widely applied in empirical demand studies in order to limit the number of estimated parameters. For detailed developments of the notion the reader is referred to Leontief, Sono $(1945,1961)$, Deaton and Muellbauer (1980b), Green, and Gorman $(1959,1976)$. Because of the nature of market-level data, these studies have still used aggregate commodities in the analysis. For example, they model demand for chicken as opposed to demand for whole bird fryers and demand for parts/processed chicken. Implicit in such a formulation is that chicken must be strongly separable from other commodities. ${ }^{3}$ Violation of this restriction would have an impact on the results of tests for structural change. Consequently, it is of interest to test a more disaggregated model for weak separability, a necessary condition for the existence of aggregates.

Subsequent tests for weak separability are based on Goldman and Uzawa's result. The necessary and sufficient condition for weak separability is that the off-diagonal term in the Slutsky substitution matrix is proportional to the income derivatives of the two separable goods. That is, if goods $i$ and $j$ are in separable groups $r$ and $s$, respectively, then

$$
\begin{aligned}
& S_{i j}=\Theta^{r s} \frac{\partial Q_{j}}{\partial X} \\
& \quad \text { for all } i \in r \text { and } j \in s,
\end{aligned}
$$

where $S_{i j}$ is the appropriate element in the Slutsky substitution matrix, $Q$ 's are quantities consumed, and $\Theta^{r s}$ is a factor of proportionality between groups $r$ and $s$. Intuitively, the compensated effects of price changes of goods in other groups are felt only through the reallocation of expenditures among groups.

Several consumption studies have tested for separability among broad aggregate groups (e.g., Jorgenson and Lau, Bieri and de Janvry). No one has tested for separability within groups of meat products in the United States, although Pudney tested an a priori grouping, as well as several "optimal" groupings, of twenty meat products using data from the U.K. National Food Survey. Pudney rejected weak separability in all cases.

To test for weak separability in this study,

\footnotetext{
${ }^{3}$ Somewhat less restrictive conditions, under which aggregation is "almost" correct, are discussed in Deaton and Muellbauer (1980b, pp. 129-33).
}

several a priori groupings of the meat commodities are specified, and the parameter restrictions implied by each grouping are tested using an adjusted nonlinear Wald test. ${ }^{4}$ An a priori set of utility trees is specified based on economic intuition and available data (table 1). For example, the first tree in table 1 is pictured in panel A of figure 1. Other goods and food

4 The Wald test allows us to use the unrestricted coefficients, which are easier to estimate. If the restrictions are true, then the unrestricted coefficients should come close to satisfying the restrictions. Other tests, such as the likelihood ratio test, would require a reestimation of the model with the restrictions imposed. The two tests are asymptotically equivalent.

\section{Panel A}

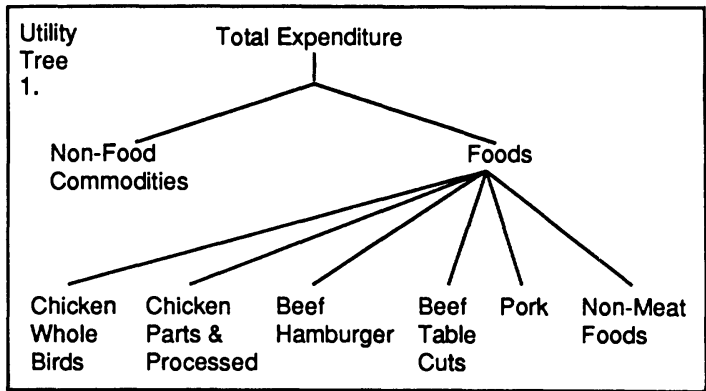

Panel B

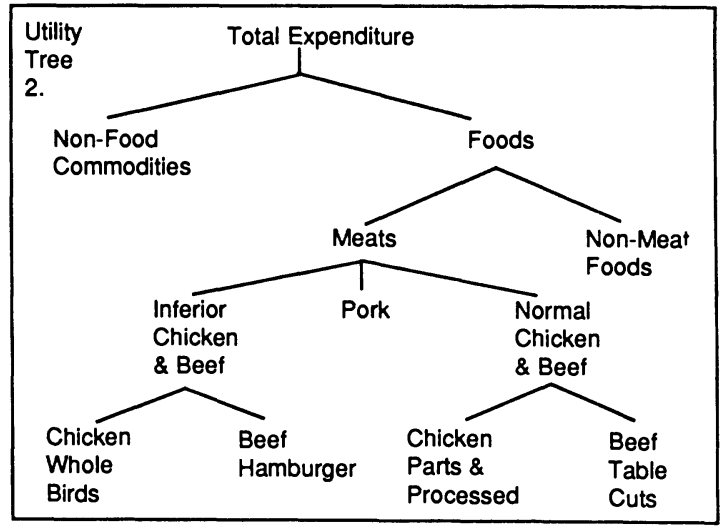

Panel C

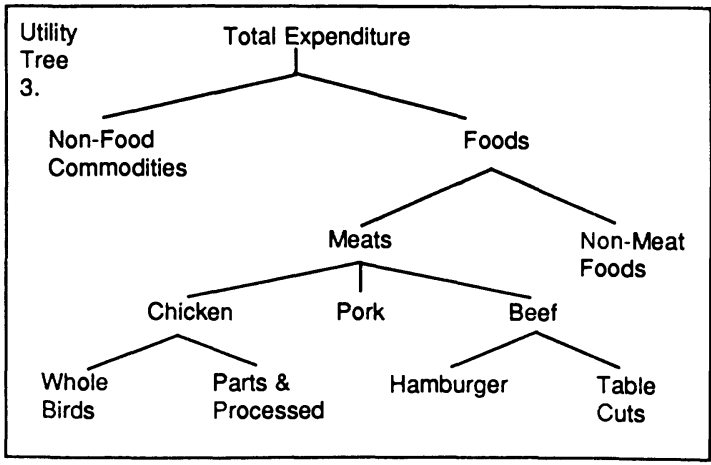

Figure 1. Example utility trees 
Table 1. Potential Utility Trees

\begin{tabular}{lcccccccc}
\hline $\begin{array}{l}\text { Utility } \\
\text { Tree }\end{array}$ & $\begin{array}{c}\text { No. of Com- } \\
\text { mod. Grps }\end{array}$ & $\begin{array}{c}\text { Whole } \\
\text { Birds }\end{array}$ & $\begin{array}{c}\text { Parts \& } \\
\text { Procssd }\end{array}$ & Hamburger & $\begin{array}{c}\text { Table } \\
\text { Cuts }\end{array}$ & Pork & $\begin{array}{c}\text { Non-Meat } \\
\text { Food }\end{array}$ & $\begin{array}{c}\text { Non-Food } \\
\text { Commod. }\end{array}$ \\
\hline 1 & 2 & A & A & A & A & A & A & B \\
2 & 5 & A & B & A & B & C & D & E \\
3 & 5 & A & A & B & B & C & D & E \\
4 & 3 & A & B & A & B & B & B & C \\
5 & 4 & A & B & A & B & B & C & D \\
6 & 4 & A & B & A & B & A & C & D \\
\hline
\end{tabular}

a In each tree, all commodities with the same letter are assumed to belong to the same group. Commodities with different letters are weakly separable.

are the only separable groups. In this case, $\Theta^{r s}$ in equation (5) takes only one value, giving the relationship between the food group, $r$, and the nonfood group, $s$. The presence of six commodities within the food group means there are fifteen $(6 ! / 4 ! 2 !)$ different ways of calculating $\Theta^{r s}$. However, of the fifteen possible restrictions only four are independent. A rejection of these four restrictions demonstrates that the separability inherent in the tree is not supported by the data. A failure to reject provides some insight into the potential existence of aggregate commodities.

The actual test involves restrictions based on equation (5), above. In generic form the restrictions for commodities $i$ and $j$ in group $r$ and $k$ in group $s$ have the form:

$$
\frac{S_{i k}}{\partial Q_{i} / \partial X}=\frac{S_{j k}}{\partial Q_{j} / \partial X}
$$

for all $i, j \in r$ and $k \in s$.

For the parameters of the AIDS model this restriction implies

$$
\begin{aligned}
& \gamma_{i k}\left(\beta_{j}+w_{j}\right)-\gamma_{j k}\left(\beta_{i}+w_{i}\right)+ \\
& \left(w_{i} \beta_{j}-w_{j} \beta_{i}\right)\left(w_{k}-\beta_{k} \ln (X / P)\right)=0 \\
& \quad \text { for all } i, j \in r \text { and } k \in s,
\end{aligned}
$$

which is tested locally at the mean shares.

Small sample properties of the Wald test are unknown. The monte-carlo evidence indicates that the empirical size of the test statistic may be much smaller than the nominal size, i.e., the type I error is too small (Gregory and Veall; Laitinen; Bera, Byron, and Jarque). The recommendation in this case is to apply an appropriate degrees of freedom correction to the statistic and then use the cutoff of the appropriate $F$-distribution (Judge et al.). The adjusted test gives type I error, which is closer to that which is specified in finite samples. Both tests are presented in the results.

In contrast to separability, the concept of structural change does not have a strong theoretical foundation. Evidence of change in parameters may not indicate an actual change in preferences but simply misspecification of the model. Nonparametric estimates of demand and estimates of highly flexible functional forms have brought into question earlier findings of structural change in red meats (Chalfant and Alston, Wohlgenant 1985). ${ }^{5}$ In this article, we take a naive approach to structural change. Changes in parameters of standard models, such that they are no longer reliable forecasters, are assumed to reflect a shift in the underlying structure of demand.

The tests for structural change consider both gradual and one-time-only shifts in the demand curve. A test of gradual, exogenous shifts in the dynamic model merely requires an intercept in equation (4). The coefficient of the intercept then indicates the exogenous shift in demand. Some studies of structural change have reported a one-time shift in red meat demand around 1974. To test for a one-time shift in the mid-1970s, the model is reestimated with an intercept dummy included. In contrast to previous studies of structural change, these tests focus on exogenous shifts in the demand curve rather than on changes in individual parameters. A multivariate Chow test that allows the slopes to change would be preferred, but data limitations make this test of dubious value here.

Econometric tests detect statistically significant shifts in parameters but reveal nothing about the causes. This type of search for change is thus a confession of ignorance (Chal-

\footnotetext{
5 Thurman notes that nonparametric tests that do not support structural change do not rule it out either.
} 
fant and Alston). In the present case, however, the a priori hypothesis is that changes in the mix of different products within meat aggregates are at the root of changes in meat demand structure. This is tested by separation of chicken and beef into their constituent products. For example, suppose the intercept dummy is significant in the aggregate chicken equation, indicating a one-time shift in demand, but is not significant in either of the chicken product equations. Then the change in chicken product mix is causing the apparent shift in aggregate chicken demand and there is no real change in preference for chicken. Alternatively, if a corresponding structural change occurs in one or both of the chicken product equations, then consumer preferences for chicken have changed.

\section{Data}

Annual data covering 1965-85 are used in the estimation. Retail-weight meat consumption data, retail prices of beef and pork, the nonfood CPI, and food CPI are from various issues of Food Consumption, Prices and Expenditures (USDA). Personal consumption expenditures and food expenditures are the latest revised series obtained directly from the Department of Commerce. The food CPI and food expenditures are converted to a non-meat foods basis. Total expenditures are adjusted to representative expenditures with a $k$ index calculated from the distribution of family incomes reported by the U.S. Bureau of the Census.

Beef is disaggregated into hamburger and table cuts according to fed and nonfed slaughter from Livestock Slaughter, following the procedure suggested by Wohlgenant (1986). The breakdown of federally inspected broiler slaughter by product type is from various issues of Poultry Slaughter. Total chicken consumption per capita is allocated among product type based on the proportions in the federal slaughter.

Data on the retail price of whole birds is obtained from Food Consumption, Prices and Expenditures (USDA). The retail prices of chicken parts and aggregate chicken are derived as follows. Wholesale prices of whole birds and various chicken parts are obtained from Poultry Market Statistics. A weightedaverage wholesale parts price is calculated based on the proportion of different parts ob- tained from a whole bird. This wholesale parts price is converted to a retail parts price based on the relationship between the wholesale and retail prices of whole birds. An aggregate chicken price is then constructed from a quantity-share-weighted-average of the retail whole and parts prices. This chicken price is more comparable to the beef and pork retail prices, which are both weighted averages of the retail prices of different cuts, than the whole bird retail price that has been used in past analysis.

\section{Results}

Results for the aggregate and disaggregated meat models are reported in tables 2 and 3; compensated elasticities are in tables 4 and 5 . In the aggregate model, the coefficients are reasonable in signs and magnitude, and significant for the most part. The significant complementarity of other goods in chicken and pork equations are exceptions. The equations in the disaggregated model are respecified with aggregate chicken split into whole birds and cut up parts plus processed consumption; aggregate beef is divided into hamburger and table cuts. The results for this model also have reasonable signs and magnitude, but there are fewer significant price elasticities. ${ }^{6}$ The disaggregated model reveals more complex relationships among the meat products than the aggregate model.

The results for aggregate chicken and beef reflect the underlying elasticities of their constituent products and for chicken, the changing share of products over time. The average own-price elasticities for both aggregate chicken and beef (table 4) are smaller in absolute value than the own-price elasticities of their respective products (table 5). The average own-price response for each meat aggregate is reduced by the substitution between products.

\footnotetext{
${ }^{6}$ The Durbin-Watson statistics (D-W), while having unknown distributions in multiequation models, indicate some negative autocorrelation in the residuals, particularly in pork, food, and hamburger. Berndt and Savin show that such negative autocorrelation must take a form which is consistent with the adding-up property of expenditure-share demand systems. (For an empirical application to meat, see Bewley and Young.) Negative autocorrelation could be the result of the first difference form of the model, but this does not appear to be the case. Instead, it stems from large (three or more standard errors from zero) residuals in many of the equations in 1975. Dummying out this particular observation produced D-Ws close to two in all equations except for other foods. The effects on the model's parameters were marginal in terms of magnitudes, signs, and significance. The problem with this solution is that it deprives the model of potentially significant information; thus, the results without the dummy are reported.
} 
Table 2. Aggregate Meat Model

\begin{tabular}{|c|c|c|c|c|c|c|c|c|c|c|}
\hline & Chicken & Beef & Pork & Food & Other & $\begin{array}{l}\text { Expendi- } \\
\text { tures }\end{array}$ & $\begin{array}{l}\text { Inter- } \\
\text { cept }\end{array}$ & $\begin{array}{c}\text { Average } \\
\text { Budget } \\
\text { Share }\end{array}$ & $R^{2}$ & $\begin{array}{l}\text { Durbin- } \\
\text { Watson }\end{array}$ \\
\hline Chicken & $\begin{array}{l}.377^{* a} \\
(.022)\end{array}$ & $\begin{array}{l}.124^{*} \\
(.042)\end{array}$ & $\begin{array}{l}.007 \\
(.023)\end{array}$ & $\begin{array}{c}-.180^{*} \\
(.087)\end{array}$ & $\begin{array}{c}-.328^{*} \\
(.078)\end{array}$ & $\begin{array}{r}-.247^{*} \\
(.108)\end{array}$ & $\begin{array}{l}.008^{*} \\
(.003)\end{array}$ & .0052 & .959 & 1.68 \\
\hline Beef & $\begin{array}{l}.124^{*} \\
(.042)\end{array}$ & $\begin{array}{l}1.043^{*} \\
(.288)\end{array}$ & $\begin{array}{l}.413^{*} \\
(.127)\end{array}$ & $\begin{array}{c}-.817 \\
(.543)\end{array}$ & $\begin{array}{c}-.763 \\
(.524)\end{array}$ & $\begin{array}{r}-1.624 \\
(.845)\end{array}$ & $\begin{array}{l}.000 \\
(.025)\end{array}$ & .0248 & .632 & 2.03 \\
\hline Pork & $\begin{array}{c}.007 \\
(.023)\end{array}$ & $\begin{array}{l}.413^{*} \\
(.127)\end{array}$ & $\begin{array}{l}.315^{*} \\
(.102)\end{array}$ & $\begin{array}{c}.014 \\
(.318)\end{array}$ & $\begin{array}{c}-.749^{*} \\
(.308)\end{array}$ & $\begin{array}{c}-.973 \\
(.491)\end{array}$ & $\begin{array}{c}-.008 \\
(.014)\end{array}$ & .0135 & .672 & 2.94 \\
\hline Food & $\begin{array}{c}-.180^{*} \\
(.087)\end{array}$ & $\begin{array}{c}-.817 \\
(.543)\end{array}$ & $\begin{array}{l}.014 \\
(.318)\end{array}$ & $\begin{array}{c}4.589 * \\
(1.952)\end{array}$ & $\begin{array}{c}-3.606^{*} \\
(1.852)\end{array}$ & $\begin{array}{c}-8.858^{*} \\
(2.340)\end{array}$ & $\begin{array}{c}-.010 \\
(.068)\end{array}$ & .1646 & .610 & 2.80 \\
\hline
\end{tabular}

Note: All coefficients are multiplied by 100 for ease of presentation. Figures in parentheses are standard errors.

angle asterisk indicates significant at a .05 level.

Cross-price substitution effects between the two chicken products and between the two beef products are all significant and fairly large.

The income results for individual meat products agree with cross-section results (Haidacher et al.). Whole birds and hamburger are inferior goods, and chicken parts/ processed and beef table cuts are normal goods. Aggregate beef and chicken income effects are dominated by the income elasticities of the normal products. ${ }^{7}$

The average cross-price elasticities between chicken and beef in table 4 are primarily due to the strong cross-price effects between hamburger and whole birds (table 5). The significant cross-price effect between aggregate beef and pork is due to the substitution between hamburger and pork. Although crossprice substitution is not significant between aggregate chicken and pork, it is significant between chicken parts/processed and pork.

Separability tests using the disaggregated model show how consumers approach thè allocation of the meat budget. The set of utility trees tested for weak separability is in table 1 , and trees 1,2 , and 3 are illustrated in figure 1 . The results of the Wald tests of the separability restrictions are in table 6 . Due to the tendency of Wald tests to over-reject in finite samples, the adjusted Wald results are more appropriate. Trees $3,4,5$, and 6 are rejected at

\footnotetext{
${ }^{7}$ Use of representative expenditure, $X^{o}$, rather than average expenditure, $X$, does not appreciably alter the overall statistical performance of the modcl, perhaps because the two are very highly correlated at $\mathbf{9 9 9 5}$. The lack of significant differences between the two series may be due to the use of only five household income groups available in aggregate data to construct the $k$ index. Although the differences were not significant, the expenditure elasticity estimated with $\boldsymbol{X}^{o}$ was slightly smaller for chicken and slightly larger for beef, as predicted by Unnevehr's findings.
}

a $5 \%$ level of significance. Trees 1 and 2 are not rejected.

In tree 3 (panel C, fig. 1), which is rejected, products are grouped according to animal origin. ${ }^{8}$ Trees 1 and 2 are not rejected, and these allow consumers to choose among products across animal origin. In tree 1 the budget is allocated between foods and nonfoods and within foods among nonmeats and all meat products at one level (panel A). Tree 2 consists of four budget allocation stages (panel B). In the first stage, expenditure is allocated between nonfood and food and in the second stage between meats and nonmeat foods. At the third stage consumers allocate within meats among three groups: pork, lower quality chicken and beef, and higher quality chicken and beef. At the final stage, consumers allocate between products within the normal and inferior meat categories.

The separability tests suggest that consumers choose among meat products rather than among meat aggregates of a particular animal origin. In tree 2 , for example, the marginal rate of substitution between whole birds and hamburger is independent of changes in quantities consumed of either table cuts or parts/ processed. These results call into question the usefulness of analyzing demand for aggregate beef or chicken. They suggest that a full understanding of meat demand or tests for structural change requires analysis of a disaggregated meat products model.

Before considering the tests for structural change, it should be noted that the AIDS can impose restrictions on the evolution of elas-

\footnotetext{
${ }^{8}$ Several other tree configurations in which meat products were grouped by animal origin were tested. All were rejected, and tree 3 is representative.
} 


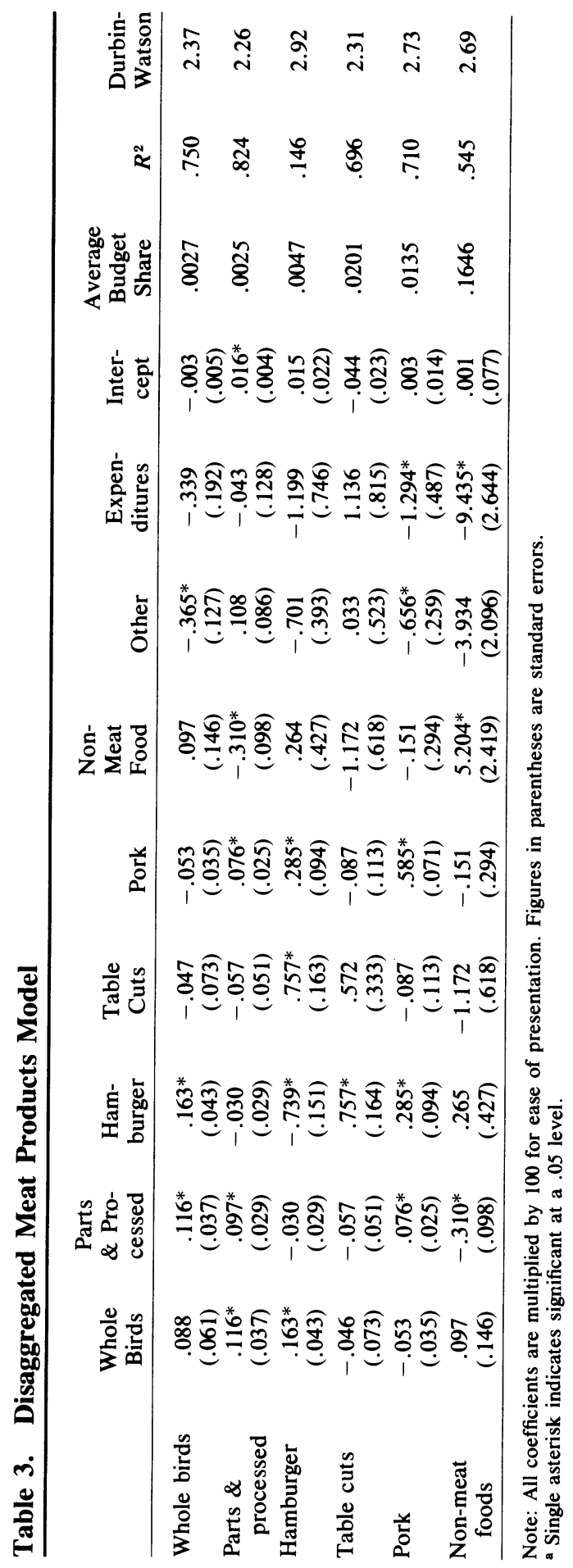


Table 4. Compensated Aggregate Meat Elasticities

\begin{tabular}{lrrrrrr}
\hline & $C H K$ & $B F$ & $P K$ & \multicolumn{1}{c}{ FD } & \multicolumn{1}{c}{ OTH } & EXP \\
\hline Chicken & -0.276 & 0.250 & 0.021 & -0.258 & -0.210 & 0.527 \\
Beef & 0.052 & -0.570 & 0.171 & -0.273 & -0.035 & 0.344 \\
Pork & 0.007 & 0.314 & -0.762 & 0.056 & -0.336 & 0.278 \\
Food & -0.008 & -0.038 & 0.007 & -0.642 & 0.160 & 0.479 \\
\hline
\end{tabular}

Note: In the AIDS model the compensated elasticities are given by

$$
e_{i j}^{*}=\frac{\gamma_{i j}}{w_{i}}-\delta_{i j}+w_{j}\left[\frac{\beta_{i}}{w_{i}}+1\right] \text {, }
$$

where $\delta_{i j}$ is the Kronecker delta and the average budget shares in tables 1 and 2 are used.

Table 5. Compensated Disaggregate Meat Products Elasticities

\begin{tabular}{|c|c|c|c|c|c|c|c|c|}
\hline & $W H L$ & $P \& P$ & $H B$ & $T C$ & $P K$ & $F D$ & OTH & $E X P$ \\
\hline Whole birds & -0.677 & 0.426 & 0.600 & -0.176 & -0.198 & 0.317 & -1.540 & -0.248 \\
\hline \multicolumn{9}{|l|}{ Parts \& } \\
\hline processed & 0.464 & -0.610 & -0.117 & -0.210 & 0.315 & -1.101 & 1.086 & 0.827 \\
\hline Hamburger & 0.346 & -0.069 & -2.593 & 1.593 & 0.590 & 0.310 & -2.750 & -1.573 \\
\hline Table cuts & -0.019 & -0.024 & 0.384 & -0.684 & -0.022 & -0.325 & 1.256 & 1.565 \\
\hline Pork & -0.039 & 0.057 & 0.212 & -0.064 & -0.565 & -0.105 & -0.455 & 0.040 \\
\hline $\begin{array}{l}\text { Non-meat } \\
\text { foods }\end{array}$ & 0.007 & -0.018 & 0.018 & -0.063 & -0.003 & -0.614 & 0.099 & 0.427 \\
\hline
\end{tabular}

Note: In the AIDS model the compensated elasticities are given by

$$
e_{i j}^{*}=\frac{\gamma_{i j}}{w_{i}}-\delta_{i j}+w_{j}\left[\frac{\beta_{i}}{w_{i}}+1\right],
$$

where $\delta_{i j}$ is the Kronecker delta and the average budget shares in tables 1 and 2 are used.

\begin{tabular}{|c|c|c|c|c|c|c|c|}
\hline $\begin{array}{l}\text { Utility } \\
\text { Tree }\end{array}$ & $\begin{array}{l}\text { Wald } \\
\text { Test }\end{array}$ & $D F$ & $\begin{array}{c}.05 \\
\text { Cutoff } \\
\end{array}$ & $\begin{array}{c}\text { Adjusted } \\
\text { Wald Test }^{\mathrm{a}} \\
\end{array}$ & $D F 1$ & $D F 2$ & $\begin{array}{l}.05 \\
\text { Cutoff }\end{array}$ \\
\hline 1 & 6.648 & 5 & 11.070 & .945 & 5 & 81 & 2.34 \\
\hline 2 & 25.049 & 9 & 16.919 & 1.978 & 9 & 81 & 2.02 \\
\hline 3 & 55.438 & 9 & 16.919 & 4.377 & 9 & 81 & 2.02 \\
\hline 4 & 531.413 & 11 & 19.675 & 34.326 & 11 & 81 & 1.94 \\
\hline 5 & 48.299 & 11 & 19.675 & 3.120 & 11 & 81 & 1.94 \\
\hline 6 & 64.901 & 11 & 19.675 & 4.192 & 11 & 81 & 1.94 \\
\hline
\end{tabular}

Table 6. Weak Separability Test Results

a The adjusted Wald-statistic is calculated:

$$
W^{*}=\frac{W / q}{M T /(M T-K)},
$$

where $W$ is the regular Wald statistic, $q$ is the number of restrictions in the test, $M$ is the number of equations in the system, $T$ is the

\begin{tabular}{|c|c|c|c|c|c|c|c|c|}
\hline & Chk & $\begin{array}{l}\text { Whl } \\
\text { Brds }\end{array}$ & $\begin{array}{l}\text { Parts } \\
\& \text { Prc }\end{array}$ & Beef & Hamburger & $\begin{array}{c}\text { Tbl } \\
\text { Cuts }\end{array}$ & Pork & $\begin{array}{c}\text { Non-Meat } \\
\text { Food }\end{array}$ \\
\hline$I N T R C P T^{\mathrm{a}}$ & $\begin{array}{l}.013^{* \mathrm{~b}} \\
(.003)\end{array}$ & $\begin{array}{l}.001 \\
(.007)\end{array}$ & $\begin{array}{l}.017^{*} \\
(.005)\end{array}$ & $\begin{array}{c}-.049 * \\
(.023)\end{array}$ & $\begin{array}{l}.005 \\
(.030)\end{array}$ & $\begin{array}{c}-.070^{*} \\
(.026)\end{array}$ & $\begin{array}{c}-.004 \\
(.018)\end{array}$ & $\begin{array}{l}.028 \\
(.097)\end{array}$ \\
\hline$D 74$ & $\begin{array}{c}-.010^{*} \\
(.005)\end{array}$ & $\begin{array}{c}-.008 \\
(.007)\end{array}$ & $\begin{array}{c}-.002 \\
(.005)\end{array}$ & $\begin{array}{l}.109 * \\
(.031)\end{array}$ & $\begin{array}{l}.024 \\
(.040)\end{array}$ & $\begin{array}{l}.078^{*} \\
(.034)\end{array}$ & $\begin{array}{c}.019 \\
(.024)\end{array}$ & $\begin{array}{c}-.086 \\
(.132)\end{array}$ \\
\hline
\end{tabular}
number of observations, and $K$ is the number of free parameters in the system (see Judge et al., p. 475).

Table 7. Structural Change in Demands for Aggregated and Disaggregated Meat Products

a Coefficients and standard errors are multiplied by 100 for ease of presentation.

${ }^{b}$ Asterisk indicates significant at a .05 level. 
ticities with changes in real expenditures (Wohlgenant 1984); these restrictions might bias the trend variable results. For the AIDS model, Wohlgenant shows that

$$
\partial e_{i i} / \partial \ln (X)=\left(1+e_{i i}\right)\left(1-e_{i}\right),
$$

where $e_{i i}$ and $e_{i}$ represent own-price and expenditure elasticities, respectively. An aggregate commodity such as food, which is inelastic with respect to both own-price and income, will become less price elastic in the AIDS model as income grows. For less aggregated commodities, such as whole birds or hamburger, the magnitudes and even the signs of the elasticities cannot be specified a priori, so that the partial derivative in equation (8) can have any sign. Examination of table 4 indicates that aggregate meats will become less price elastic as income grows. In the disaggregated results (table 5), however, both hamburger and table cut beef become more price elastic as expenditures increase. Because the sign of the partial derivative in equation (8) is not fixed for disaggregated commodities, the exogenous trends in the AIDS model are not artifacts imposed by the functional form. ${ }^{9}$

Evidence regarding structural change in the aggregated and disaggregated models is found in the intercept results in tables 2 and 3 . The intercept is equivalent to a time trend in the static model; it allows for exogenous growth or decline in the share of each of the commodities, in addition to the effects of changes in relative prices and income. In the aggregate model, the intercept is significant only in chicken, where it is large and positive. This indicates rapid growth in the share of chicken independent of relative price movements. In

\footnotetext{
${ }^{9}$ The disaggregated system was reestimated as a Rotterdam model to further examine the influence of functional form. In the Rotterdam system, the partial derivative of the own*price elasticity with respect to income is $e_{i i}\left(1-e_{i}\right)$. Hence, the Rotterdam system implies price reactions to changes in income opposite of those of the AIDS model for many values of elasticities. Estimated elasticities from the Rotterdam model were very close to those in the AIDS model. The separability results were qualitatively similar, with the Wald test rejecting only the trees which separated by animal type as represented by tree 3 , but the unadjusted Wald test no longer rejected any of the specifications. Barnett (1979b) has shown that if individual consumers' preferences are of the Rotterdam form, then the market demands will be Rotterdam and obey the typical demand restrictions. He derives a necessary but not sufficient condition on the market demand parameters if the individual preferences are weakly separable (Barnett 1979a). Thus, the separability results must be tempered. The AIDS model test incorporates the maintained hypothesis of the "representative consumer,' while Barnett's results show the Rotterdam system is not subject to this caveat. Of course, failure to reject weak separability does not imply that preferences are separable in either model. Given the differing interpretations of the two models, the similarity of the results is comforting.
}

other meats and foods, the exogenous factors have been static or have shown a small decline over time. In the disaggregated model, the intercept is significant, large, and positive only in the chicken/part processed equation, while whole birds and beef table cuts declined. Thus, the apparent growth in aggregate chicken is due to growth in the demand for parts/processed.

A second test for structural change considers a shift in demand in the mid-1970s. An intercept dummy which is 1 from 1965 through 1974 and 0 thereafter is included. In general, the parameter results were very similar, so only intercept and dummy estimates for aggregate meats and the four products are reported in table 7 . In aggregate meats, the dummy is significant and negative in the chicken share equation, indicating that exogenous demand growth was slower before 1974 than after 1974. Both dummy and constant are significant in aggregate beef; their coefficients indicate that beef share increased before 1974 and declined afterwards. The dummy is insignificant in pork and other foods.

Dummy and intercept results in the disaggregated model show that change in total beef demand growth was a result of similar underlying changes in demand for table cuts. Demand for table cuts declined after 1974, while demand for hamburger did not. The two chicken product equations show no shift in growth rate in the mid-1970s. Changes in shares of chicken products are explained by movements in relative prices and income, and constant exogenous growth in demand for parts. The apparent shift in growth of aggregate chicken after 1974 is explained by the increased share of parts in total chicken over time. ${ }^{10}$

Intercept results in the disaggregated model indicate a significant exogenous growth in demand for parts/processed, while demand for whole birds declined. It is interesting to consider the possible chicken budget shares and consumption in 1985 if preferences had remained constant. The following shows the 1985 budget share and quantity consumed if 1985 prices and incomes prevailed without exogenous growth in demand:

\footnotetext{
10 The weighted sum of the intercepts in the whole and parts/ processed equations increases from .003 before 1974 to .008 after 1974. The average weights for the period before 1974 were $66 \%$ whole birds and 34\% parts/processed; for the years after 1974 the average weights changed to $45 \%$ whole birds and $55 \%$ parts/ processed.
} 


\begin{tabular}{lcccccc} 
& \multicolumn{2}{c}{1965} & \multicolumn{2}{c}{1985 Actual } & \multicolumn{2}{c}{1985 Preference } \\
& Share & Quantity & Share & Quantity & Share & Quantity \\
Whole & .0038 & 24.7 & .0011 & 16.3 & .0017 & 25.9 \\
Parts & .0016 & 8.6 & .0035 & 41.8 & .0003 & 3.6 \\
Total & .0054 & 33.3 & .0046 & 58.0 & .0020 & 29.5
\end{tabular}

This comparison reveals that the shift in preferences toward parts and processed products has been extremely important. Without the change in preferences, consumption of total chicken would have been virtually the same in 1985 as in 1965. Proportion of whole to total chicken would have increased slightly, while the proportion of parts/processed to total chicken would have declined. The predicted decline in parts/processed is due to the increase in the parts price relative to the whole bird price over this period.

\section{Concluding Comments}

Two dynamic almost ideal demand systems were estimated, one for aggregate meats and one for disaggregated meat products. The results reveal how demand for aggregate beef and chicken reflects the more varied demand for their constituent products. These timeseries estimates confirm cross-section results that hamburger and whole birds are inferior goods and chicken parts and beef table cuts are normal goods. Results also showed that most cross-price substitution between beef and chicken is from substitution between whole birds and hamburger. This finding agrees with Wohlgenant's (1986) disaggregated estimates of beef demand, which showed that most beef-poultry substitution is between hamburger and poultry.

Tests for structural change in the aggregate meats with this particular model and data set showed a preference shift away from beef and toward chicken after 1974. These results are roughly consistent with the findings of other studies of structural change. Most other researchers found that in the mid-1970s beef demand became less elastic with respect to own price (Chavas) and income (Chavas, Frank, Hudson and Vertin) while chicken became a stronger substitute for beef (Braschler, Moschini and Meilke, Frank) or more responsive to income (Chavas, Hudson and Vertin). Previous tests for structural change in aggregate meat models generally indicate a saturated market for beef and an increased preference for chicken after 1974.
Tests for weak separability among meat products, however, suggest that tests for structural change in the aggregate meats may be biased. The hypothesis that consumers allocate expenditures first to animal product aggregates such as beef or chicken, and then among products within an aggregate was rejected. In the budget allocation trees not rejected, consumers allocate expenditure across all meat products at once or between high quality and low quality products from different animals. Use of aggregate chicken and beef could bias estimation of demand parameters and hence tests for structural change.

As the separability results suggest, tests for structural change in disaggregated products reveal a different picture of preference changes than the aggregate model. Two types of significant shifts in meat demand were identified in meat products: an exogenous constant annual $6.4 \%$ growth in demand for chicken parts/processed from 1965 to 1985 and a $3.5 \%$ decline in demand for beef table cuts after 1974. Over the entire period, demand for whole birds declined slightly and demand for hamburger increased slightly.

Structural change in aggregate beef demand reflected the decline in table cut demand. Aggregate chicken changes, however, followed both the increase in parts/processed demand and the change in the mix of chicken products marketed. An apparent increased rate of growth in aggregate chicken demand after 1974 is due to the larger share of parts/ processed in aggregate chicken after 1974 rather than an increased rate of change in preference.

Product equations revealed two other features of structural change. First, they show that timing of structural change in beef and chicken differed. Change in chicken demand has been ongoing for the past twenty years, while change in beef demand occurred after 1974. Second, although most beef-chicken cross-price substitution takes place between hamburger and whole birds, the change in preferences since 1974 led to substitution of chicken parts for beef table cuts. Thus crossprice effects are important for inferior meat products, but preference shifts are important in explaining changes in demand for high quality meat products.

The concentration of the beef-poultry preference shift in particular products calls into question the hypothesis that health concerns have been the driving force behind the shift 
from beef to chicken (Chavas). A shift in demand due purely to health concerns would have led to growth in whole birds and a decline in hamburger, which we did not find. While awareness of cholesterol may be greater among consumers of high quality meats, the shift from beef table cuts to chicken parts/ processed must also have been caused by growth in demand for convenience. Significant growth in parts/processed may have been fostered by growth in fast food outlets as suggested by Wohlgenant (1986).

Growth in the preference for chicken parts/ processed is extremely important in explaining observed chicken consumption. If preferences had remained constant between 1965 and 1985 , quantities of whole birds and parts consumed would have remained virtually the same. Increased demand for convenience is a plausible explanation for the growth in chicken parts demand because the value of time for the principal meal preparer has increased during the last twenty-five years. Between 1960 and 1985, the proportion of women who work outside the home increased from $35 \%$ to $50 \%$, households headed by women increased from $18 \%$ to $28 \%$, and single-person households increased from $13 \%$ to $24 \%$ of all households (U.S. Bureau of the Census). These trends should have increased the demand for embodied services in food products. The findings here suggest that the chicken industry has responded to these changing preferences through marketing new products. Therefore, product development must play an important role in any effort to stimulate beef demand.

\section{[Received May 1987; final revision received October 1987.]}

\section{References}

Barnett, W. "The Joint Allocation of Leisure and Goods Expenditure." Econometrica 47(1979a):539-63.

- Theoretical Foundations for the Rotterdam Model." Rev. Econ. Stud. 46(1979b):109-30.

Bera, A., R. Byron, and C. Jarque. "Further Evidence on Asymptotic Tests of Homogeneity and Symmetry in Large Demand Systems." Econ. Letters 8(1981): 101-105.

Berndt, E., and E. Savin. "Estimation and Hypothesis Testing in Singular Equation Systems with Autoregressive Disturbances.' Econometrica 43(1975):93757.

Bewley, R., and T. Young. "Applying Theil's Multinomial Extension of the Linear Logit Model to Meat
Expenditure Data." Amer. J. Agr. Econ. 69(1987): 151-57.

Bieri, J., and A. de Janvry. "Empirical Analysis of Demand Under Consumer Budgeting." Giannini Foundation Monograph No. 30, University of California, Berkeley, Sep. 1972.

Blanciforti, L., R. Green, and G. King. "U.S. Consumer Behavior over the Postwar Period: An Almost Ideal Demand System Analysis." Giannini Foundation Monograph No. 40. University of California, Davis, Aug. 1986.

Braschler, C. "The Changing Demand Structure for Pork and Beef in the 1970s: Implications for the 1980s." $S$. J. Agr. Econ. 15(1983): 105-10.

Capps, O., J. Tedford, and J. Havlicek. "Household Demand for Convenience and Nonconvenience Foods." Amer. J. Agr. Econ. 67(1985):862-69.

Chalfant, J., and J. Alston. "Accounting for Changes in Tastes." California Agr. Exp. Sta. Work. Pap. No. 402, Giannini Foundation of Agr. Econ., July 1986.

Chavas, J.-P. "Structural Change in the Demand for Meat." Amer. J. Agr. Econ. 65(1983):148-53.

Dahlgran, R. "The Changing Structure of U.S. Meat Demand: Implications for Meat Price Forecasting.' Proceedings of the NCR-134 Conference on Applied Commodity Price Analysis, Forecasting, and Market Risk Management, St. Louis, MO, 22-23 Apr. 1986.

Deaton, A., and J. Muellbauer. "An Almost Ideal Demand System." Amer. Econ. Rev. 70(1980a):312-26.

- Economics and Consumer Behavior. Cambridge MA: Cambridge University Press, 1980b.

Frank, M. D. "Structural Change in the Retail Demand for Beef, Chicken, and Pork: An Application of Gradual Switching Regression." Ph.D. thesis, University of Illinois, 1984.

Goldman, S., and H. Uzawa. "A Note on Separability in Demand Analysis.' Econometrica 32(1964):387-98.

Gorman, W. "Separable Utility and Aggregation." Econometrica 27(1959):469-81.

_. "Tricks with Utility Functions." Essays in Economic Analysis, ed. M. Artis and R. Nobay. Cambridge: Cambridge University Press, 1976.

Green, H. A. J. Aggregation in Economic Analysis: An Introductory Survey. Princeton NJ: Princeton University Press, 1964.

Gregory, A., and M. Veall. "Formulating Wald Tests of Nonlinear Restrictions." Econometrica 53(1985): 1465-68.

Haidacher, R. C., J. A. Craven, K. S. Huang, D. M. Smallwood, and J. R. Blaylock. Consumer Demand for Red Meats, Poultry, and Fish. Washington DC: U.S. Department of Agriculture, Econ. Res. Serv., NED, Sep. 1982.

Hudson, M. A., and J. P. Vertin. "Income Elasticities for Beef, Pork, and Poultry: Changes and Implications." J. Food Distrib. Res. 1(1985):25-85.

Judge, G., W. Griffiths, R. Hill, H. Lutekpohl, and T. Lee. The Theory and Practice of Econometrics. New York: John Wiley \& Sons, 1986.

Laitinen, K. "Why Is Demand Homogeneity So Often Rejected?" Econ. Letters 1(1978): 187-91. 
Leontief, W. "A Note on the Interrelation of Subsets of Independent Variables of a Continuous Function with Continuous First Derivatives." Bull. Amer. Math. Soc. 53(1947):343-50.

Jorgenson, D., and L. Lau. "The Structure of Consumer Preferences." Ann. Econ. and Soc. Measure. 4 (1975):49-101.

Moschini, G., and K. D. Meilke. "The U.S. Demand for Beef-Has There Been a Structural Change?' West. J. Agr. Econ. 9(1984):271-82.

Pope, R., R. Green, and J. Eales. "Testing for Homogeneity and Habit Formation in a Flexible Demand Specification of U.S. Meat Consumption." Amer. J. Agr. Econ. 62(1980):778-84.

Pudney, S. "An Empirical Method of Approximating the Separable Structure of Consumer Preferences." Rev. Econ. Stud. 48(1981):561-77.

Sono, M. "The Effect of Price Changes on the Demand and Supply of Separable Goods." Kokumin Keisai Zasshi 74(1945):1-51.

. "The Effect of Price Changes on the Demand and Supply of Separable Goods." Int. Econ. Rev. 2(1961): 239-71.

Thurman, W. "The Poultry Market: Demand Stability and Industry Structure." Amer. J. Agr. Econ. 69(1987): 30-37.

Unnevehr, L. J. "Income Distribution and Structural Change in U.S. Meat Demand." Selected Paper presented at AAEA annual meeting, Reno NV, July 1986.
U.S. Department of Agriculture. Food Consumption, Prices, and Expenditures. Washington DC, selected issues.

_. Livestock Slaughter. Washington DC, selected issues.

- Poultry Slaughter. Washington DC, selected issues.

- Poultry Meat Statistics. Washington DC, selected issues.

U.S. Department of Commerce, Bureau of the Census. Current Population Reports, P-60, Washington DC, various issues.

- Statistical Abstract of the Unites States.

Wohlgenant, M. "Conceptual and Functional Form Issues in Estimating Demand Elasticities for Food.' Amer. J. Agr. Econ. 66(1984):211-15.

. "Effects of the Changing Composition of Beef Consumption on the Elasticities for Beef and Poultry." Paper presented at the S-165 Symposium, "The Demand for Meat: What Do We Know and What Does it Mean?' Charleston SC, 20-21 Oct. 1986.

- "Estimating Cross Elasticities of Demand for Beef." West. J. Agr. Econ. 10(1985):322-29.

Zellner, A. "An Efficient Method of Estimating Seemingly Unrelated Regressions and Tests of Aggregation Bias." J. Amer. Statist. Assoc. 57(1962):348-68. . "Estimators for Seemingly Unrelated Regression Equations: Some Exact Finite Sample Results." J. Amer. Statist. Assoc. 58(1963):977-92. 